\title{
MULHERES NEGRAS, ESCOLARIDADE, SEXISMO E SUBORDINAÇÃO: IDENTIDADES EX-POSTAS NA SALA DE AULA
}

\author{
Terezinha Oliveira Santos
}

RESUMO: Neste artigo, retomo dois trechos da minha tese de doutorado ${ }^{1}$ que tratam de construção de identidades, numa reflexão que enfoca a condição da mulher na sala de aula, seja ela estudante ou professora, numa perspectiva (auto) etnográfica a partir de leitura de alguns teóricos que abordam questões de sexismo e subordinação. Assim, a partir de uma descrição de algumas cenas do cotidiano de mulheres negras, conjunto no qual me incluo, procuro refletir sobre o sexismo e as condições de subordinação e dominação presentes, principalmente, nas práticas cotidianas onde nós estamos inseridas.

PALAVRAS-CHAVE: Experiência cotidiana. Resistência. Resiliência.

ABSTRACT : In this article, I return two sections of my doctoral thesis dealing with identity construction, a reflection that focuses on women's status in the classroom, whether student or teacher, a perspective (auto) ethnographic from reading some theorists addressing issues of sexism and subordination. Thus, from a description of some scenes of everyday black women, set in which I include myself, I try to think about sexism and conditions of subordination and domination, especially in daily practices where we are inserted.

KEYWORDS: Everyday experience. Resistance. Resilience.

A narrativa, que durante tanto tempo floresceu num meio de artesão - no campo, no mar e na cidade -, é ela própria, num certo sentido, uma forma artesanal de comunicação. Ela não está interessada em transmitir o "puro em si" da coisa narrada como uma informação ou um relatório. Ela mergulha a coisa na vida do narrador para em seguida retirá-la dele. Assim se imprime na narrativa a marca do narrador, como a mão do oleiro na argila do vaso.

Walter Benjamin

\footnotetext{
A partir de uma experiência pessoal como estudante de doutorado, tentei interferir no sistema educativo, buscando compreender de que forma uma educação hierarquicamente racializada afetava os processos de alteridade entre professores e alunos, em especial, da Educação de Jovens e Adultos de uma escola situada em Cajazeiras, bairro periférico de Salvador/Bahia.Com esse objetivo, em 2007,formei um grupo de professoras de Português língua materna, na unidade escolar onde também leciono, para apresentar e instalar uma proposta de formação docente "em serviço" atenta às necessidades de um olhar mais sensível ao reconhecimento das diferenças, sejam elas de "raça", gênero e linguagem, o que levaria os sujeitos do ensino e aprendizagem a não só discutirem formas de desigualdade, preconceitos e discriminação, como também a apontarem saídas, no sentido de enfrentamento das suas condições de existência nesse contexto, direcionadas pela utopia de uma sociedade menos desigual.
} 
A epígrafe escolhida tem o propósito de apresentar este texto como uma daquelas conversas que entabulamos quando somos convidadas por quem gosta de ouvir o Outro, no exercício da escuta sensível dos fatos vividos ou relatados pelo narrador. Para adentrar na reflexão proposta, faz-se necessário, primeiramente, que eu apresente o cenário de onde falo, ou seja, a sala de aula da Educação de Jovens e Adultos de uma escola pública situada em Cajazeiras, periferia de Salvador, Bahia. Sou moradora do entorno onde a escola está situada, o que me confere uma visão de dentro da cultura local ao estabelecer com a maioria das alunas e alunos uma relação profissional e de vizinhança. Atuei na Educação de Jovens e Adultos durante oito anos e para ela dirigir a minha atenção na pesquisa acadêmica do Mestrado e no Doutorado concluído em 2010.

\section{O FAZER DOCENTE: PERCEPÇÕES}

A minha experiência como professora de Português na Educação de Jovens e Adultos, doravante EJA, foi constituída por desafios e questionamentos acerca da prática pedagógica e pelo meu papel político naquele espaço de atuação. Desafios, a princípio, por me ver diante de sujeitos da aprendizagem excluídos da educação regular em suas diversas identidades entrecruzadas na sala de aula, configurando aquele espaço como um complexo mosaico cultural. Questionamentos, ao longo da prática, por não possuir a formação profissional específica para atuar naquele contexto de ensino/aprendizagem, um dos fatores que podem afetar a interação com os educandos e o trato pedagógico dos conteúdos didáticos e processos avaliativos. Essa gama de reflexões encadeou as demais, materializadas na dissertação de Mestrado "Constituições Identitárias numa turma da EJA: uma leitura para além das margens", defendida em 2007, no Instituto de Letras da Universidade Federal da Bahia, sob a orientação da Prof ${ }^{a}$ Dr $^{\mathrm{a}}$ America Lucia Silva César.

A interação com alunas e alunos da EJA levou-me a "vasculhar" pontos da memória, estabelecendo, assim, um diálogo íntimo com algumas lembranças, ora do contexto familiar, ora de uma experiência escolar marcada pelo silêncio e pela invisibilidade. $\mathrm{Na}$ fenda entre passado e presente, deixei escoar naquela dissertação um testemunho das formas doridas do tornar-se negra em uma sociedade na qual, cotidianamente, somos instigadas a contrariar as expectativas que recaem sobre nossas 
identidades de cor/gênero/classe social.

Necessário se fez, nesse processo, um estranhamento de mim mesma, num percurso complexo, para compreender o quanto estava envolvida pelos estereótipos raciais em suas intersecções sociolinguísticas. Desse modo, o exercício crítico da minha prática pedagógica constituiu-se o fio condutor na percepção de uma política educacional epistemicida, que nos impede de enxergar a tensão racial existente no poder da escola como uma das instituições responsáveis pela exclusão daqueles que não se encaixam no perfil estético, socioeconômico e linguístico vigente em suas normas, fato que me levou a (re) ver questões ancestrais relacionadas ao cenário histórico da aquisição da língua portuguesa pelos povos indígenas e africanos; a perversa negação a uma educação de qualidade, fato que ainda insere a maioria dos educandos das camadas populares nas estatísticas de fracasso escolar e coloca em suspenso os discursos em prol da justiça social.

A partir do lugar que ocupo no espaço político da escola e da academia, senti a necessidade de trazer para este texto questões relacionadas ao gênero na formação de professores, de um modo geral, mas com um olhar especial para a modalidade EJA, considerando o universo quantitativo das mulheres presentes e ainda ausentes nas/das salas de aula. Esse olhar alcança, também, o significativo número de mulheres no campo do ensino e gestão nas escolas públicas, uma leitura na qual se pode afirmar que tais escolas em Salvador são representadas por um "universo feminino" e negro. Sendo assim, somos mulheres/negras/professoras/alunas. Uma identidade negra nos une a partir da herança de uma ancestralidade oriunda de escravizados africanos como integrantes de um grupo que atravessa a história sob um processo de estigmatização, racialização e exclusão social, quando se percebe a sua ausência representativa nos lugares de decisão sociopolítica e econômica (MUNANGA, 2004).

Soma-se a esse contexto a minha crença de que a escola pode ser um local de empoderamento de professores e alunos se juntos aliarmos nossas forças na busca da transformação, de uma transformação que tenha em sua gênese o (re) conhecimento de quem somos, como nos vemos e como vemos o Outro com o qual nos relacionamos, nesse sentido, faz-se necessária uma formação docente que nos (re) ensine a ler para que sejamos mais atenciosas aos discursos impressos nos projetos políticos pedagógicos, nos quais, geralmente, afirmamos a escola como espaço aberto à diversidade cultural, 
enquanto continuamos repetindo o mesmo olhar colonizador travestido de respeito às diferenças. Tais discussões poderiam ter sido ampliadas na proposta de formação docente por mim esboçada, entretanto as interdições estruturais e conjunturais que se interpuseram ao longo do ano letivo de 2007, inviabilizaram a sua consecução.

Chamo de interdição estrutural a impossibilidade do afastamento da sala de aula para cumprir o meu papel como aluna de doutorado, uma vez que já havia usufruído desse direito para cursar o Mestrado. De acordo com o Art.62 ${ }^{\circ}$ da Lei 8.261 que rege o Estatuto do Magistério Público Estadual do Ensino Fundamental e Médio (p.29). De acordo com essa lei, a licença com ônus não poderá exceder a 2 (dois) anos, prorrogável por mais 1(um). Ao terminar o curso, uma nova ausência é permitida somente depois de decorrido o prazo mínimo de 5(cinco) anos.

Considerando a nossa formação histórica, o que significa para uma estudante negra a espera de cinco anos para ter acesso, novamente, ao espaço acadêmico?

A interdição conjuntural é representada pela greve da categoria de professores da escola pública, em 2007, tudo isso afetou a dinâmica da pesquisa e, com isso, a confecção da tese, composta da análise das interdições, observações e reflexões oriundas do meu trânsito pelas escolas estadual e municipal, foi aos poucos se transformando numa formação docente que aconteceu diferente do planejamento.

\subsection{NA SALA DE AULA, AS MULHERES E SUAS “LIDAS”.}

O esforço empreendido para escrever a tese, aguçava a minha sensibilidade na escuta aos problemas pertinentes a conciliação das identidades que nós, professora e alunas precisávamos acionar para dar conta das tarefas que a experiência cotidiana nos delegava. Nas salas de aula do ensino noturno, observava as jovens, algumas retornando após o período de descanso pós-parto; outras que não voltavam, pois abandonavam a identidade estudantil para se dedicar às suas crias; havia aquelas que traziam um (a) dos(as) filhos(as) e, sob reclamações da gestão, explicavam que é "porque não tinha com quem deixar"; via mulheres a lutar com o sono em salas de aula e nelas me "via". Participava das conversas das alunas donas de casa, quando saímos da escola em 
direção ao ponto de ônibus, enumerando os afazeres domésticos que ainda estavam a nos esperar. Enquanto estava à pia, lavando os pratos, nessa ter-a-pia, aproveitava para articular as ideias.

Penso em como algumas de nós, mulheres negras, temos vivenciado a categoria de gênero com essa sobrecarga de trabalho, que nos une a todas dentro de um contexto de opressão sexista e que nos rouba um tempo de sermos apenas nós mesmas. Administrar a qualidade do tempo/produtividade pela gestão escolar vai da cobrança das notas dos alunos nas cadernetas ao apontamento das faltas dos professores, e já não é novidade que parte dessa categoria está passando por graves problemas de saúde ${ }^{2}$. A impossibilidade de gerenciar um tempo para uma atividade física, os "malabarismos" empreendidos para "dar conta" de três turnos de trabalho e a dificuldade de usufruir de uma alimentação saudável em horário e espaços adequados acarretam danos ao corpo e à mente, refletindo, em grande parte, nas repetidas ausências de docentes da sala de aula e na qualidade do ensino oferecido.

A hora do "recreio", o intervalo de 20 minutos no turno diurno, pode representar para os alunos, conforme disse no trabalho anterior ${ }^{3}$, como a reunião de migrantes no pátio escolar; para os docentes, também. Geralmente é o momento de (re) encontrar os colegas, é o tempo subtraído para as confidências, trocas, queixas, risos, pois há laços de amizades ali construídos e em constante construção. O mais comum é encontrarmos colegas desmotivados (as), mulheres sobrecarregadas com uma quarta jornada de trabalho, com aqueles três turnos fora de casa e as narrativas de serem as "chefas da família", financeira e afetivamente falando, pois geralmente os pais "se vão" e os filhos ficam.

Mesmo quando na família há a figura do homem, apesar da inversão de papéis no aspecto financeiro, a mulher ainda é vista como aquela que "cuida de", e os homens como aqueles que têm "cuidado com". De acordo com Chies (2010), estudos

\footnotetext{
2 Há, no site do Sindicato dos Professores do Estado da Bahia (SINPRO-BA), artigos e teses que tratam dessa temática.

3 "O pátio da escola permite-me também uma leitura metafórica da escola/nação naquele sentido captado por Bhabha (1998) de sua interpretação de Hobsbawn, quando esse escreve a história da nação ocidental sob a ótica da margem dessa nação e do exílio de migrantes. Sendo assim, o pátio representa paradoxalmente o centro da escola e as suas margens, dentro de uma visão de escola como local da cultura estrangeira, dos estatutos legais, discursos hegemônicos, relatórios, performances educacionais, etc.. Um local onde os que estão dentro delimitam suas zonas de atuação e de unem em 'tribos"' (SANTOS, 2007, p.65).
} 
demonstram que há profissões eminentemente femininas, tais como enfermeira e professoras primárias, além do atrelamento dessas ocupações ao "cuidar de". Elas são discriminadas pela desvalorização financeira que recai sobre a subordinação implicada na relação entre "cuidar de" e rentabilidade, visto que afazeres domésticos, cuidar de crianças e/ou de idosos, são papéis da vida privada que, naturalmente, cabe à mulher exercê-los.

Observo que, quando formamos um grupo de professoras reunidas para narrar o cotidiano, falamos do processo de embotamento do corpo/desejo consumido e encaminhado ao esquecimento, seja pela falta de um (a) parceiro(a), seja pela solidão a dois, comum em certos tipos de (des)casamento, tudo isso contado no equilíbrio tragicômico necessário à sobrevivência diária. Assim, é possível encontrar na escola um grupo de mulheres felizes com sua vida conjugal e quase todas à espera, ou à procura, de um grande amor. A interrupção desse momento, seja pelos signos sonoros, como aquela campainha que soa irritantemente ou pelas chamadas verbais, quando um dos representantes da gestão escolar vem à porta nos "alertar" para o horário, sinaliza, através dessas atitudes, também a condição de igualdade alunos/professores enquanto corpos docilizados em retorno à relação subalterna. Particularmente, há dias que não gosto desse embate entre a "obediência" e a vontade de subverter a ordem.

A expressão "ir para a sala de aula", atualmente, tem adquirido para muitos(as) professores(as) significados que se apartam de uma atividade prazerosa naquela concepção de uma educação libertadora freireana, na qual o educador está empenhado em que o educando oprimido, adulto ou não, desvele o mundo e confirme a educação como um processo de busca e de possibilidades. É essa concepção que mantém o intelectual orgânico firme em seus propósitos.

A esse quadro, acrescenta-se um tempo sinalizado pelo acionamento de diversas competências profissionais, compreendidas por Bolívar (2002) como autoidentificação - o que eu sou e como os outros me reconhecem; os conhecimentos profissionais, os componentes cognitivos da sua prática e as competências, as habilidades e a capacidade para aplicá-las de maneira significativa.

As competências docentes compreendem, então, conhecimento, habilidades, atitudes e pensamento estratégico. Para ensinar não basta conhecer a matéria; é preciso, entre outras competências, transformar o saber disciplinar em conteúdos acessíveis aos alunos. (BOLIVAR, 2002, p.17). 
Alguns professores mais novos em tempo de serviço, desencantados com a profissão, estão estudando para se submeterem aos concursos públicos em outras áreas, nas quais possam ter uma vida mais tranquila financeiramente. Isso significa, entre outras coisas, viajar ao exterior, não pagar um carro em 60 meses, assegurar o direito a um bom plano de saúde, a morar em um lugar com melhor infraestrutura e, paradoxalmente, afastar seus filhos da escola pública, pagando uma educação em um colégio de "grife", ou seja, um colégio cuja visibilidade no mercado educacional o coloca no ranking dos mais confiáveis.

O sistema de ensino/aprendizagem atual está, de alguma forma, conectado com as avaliações externas à escola, via mecanismos oficiais, representados pelos provões, Enem, SAEB e tais; isso significa dizer que o ensino de qualidade é aquele que se transforma em melhores notas ao fim daqueles julgamentos. Em novembro de 2008, o Jornal A Tarde publicou matéria intitulada 'Enem revela 'fosso' entre ensino público e privado". Dos 81.713 participantes que concluíam o ensino médio, naquele ano, o aproveitamento da rede privada foi de 55,34\%, enquanto a rede pública obteve $33,06 \%$, o que deixou a Bahia no $17^{\circ}$ lugar do ranking, com a média geral de $36,79 \%$ de acertos. O resultado positivo ficou para a prova de redação, com $68,11 \%$ para os alunos da rede privada, e 56,23\% para os alunos da rede pública, fato que os colocou próximo à média nacional registrada em $57,26 \%$.

$\mathrm{Na}$ época, segundo a opinião do secretário estadual da Educação, Adeum Sauer, dois fatores colaboraram para aquele resultado: a) a concentração de alunos na rede pública baiana está acima da média nacional, já que apenas 7,4\% frequentam as escolas privadas. Em todo o Brasil, esse número chega a 19,58\%; sendo assim, há, na Bahia, 700 mil alunos nas escolas públicas e 50 mil nas escolas particulares; e b) a falta de investimento na educação estadual.

Rui Oliveira, presidente da Associação dos Professores Licenciados da Bahia (APLB), por sua vez, ressalta quatro motivos: a) as escolas particulares enfatizam a preparação para os exames seletivos: b) a sobrecarga de trabalho com danos físicos e mentais para os professores; c) o déficit de profissionais para disciplinas na área das Ciências Exatas; e d) os cursos de aceleração como parte do problema. "O MEC aponta que a Bahia fabrica exércitos de analfabetos funcionais. Aqui se fazem os 11 anos do ensino médio e fundamental em apenas cinco" (CARIBÉ, 2008, p. A7). 


\subsection{PERCALÇOS, PERCURSOS... RESISTÊNCIAS.}

A partir dos estudos que tratam de gênero e mercado de trabalho e, por conseguinte, a tentativa de uma mobilidade social (BENTO, 1995; CARNEIRO, 1995; HENRIQUES, 2002; GIACOMINI, 2006), nós, mulheres negras, professoras em ascensão no percurso acadêmico, ou não, precisamos refletir sobre notícias que nos chegam e que dão conta de uma injusta competição, ao afirmarem que as mulheres precisam de uma vantagem de cinco anos de escolaridade para lograr a mesma oportunidade que os homens possuem para suas inserções no mercado de trabalho formal.

A situação fica pior quando se trata das mulheres negras; estas, para competirem em nível de igualdade com as mulheres brancas com quatro a sete anos de estudos, precisam de oito a onze anos, ou seja, na diferença de oportunidades intragênero, as negras precisam de quatro anos a mais de estudos. Lembremo-nos de que a escolaridade não elimina as hierarquias sociais, que podem destinar às mulheres brancas os lugares na linha de frente no mercado de trabalho, independente das funções ocupadas, pois, para as mulheres negras, os lugares de representação nesse mercado ainda estão assegurados no imaginário coletivo, conforme observação de Pinho (2004), através do mito fundacional da mulata, "símbolo gracioso" da miscigenação e suas conotações sexuais; a baiana de acarajé, como uma "carreira típica" e a empregada doméstica como ícone estereotípico e uma atualização da criada ou ama de leite colonial.

Quando a mulher negra burla uma dessas "alegorias da verdade" (PINHO, 2004, p.115) e ocupa outros territórios de poder, portanto brancas geografias, não causa estranhamento a fala da juíza baiana, negra, Luislinda Dias de Valois Santos, com quem me solidarizo e parabenizo com saudações ancestrais:

Quando eu tinha 9 anos, estava começando a estudar, um professor pediu um material de desenho e meu pai coitado, não pôde comprar o que ele pediu, mas comprou outro. Quando cheguei à escola feliz da vida, ele disse: "Menina, se seu pai não pode comprar o material, deixe de estudar e vá aprender a fazer feijoada na casa dos brancos". [...] Mas sou muito impetuosa. Voltei, fui em cima dele e falei: "Não vou fazer feijoada para branco, não. Vou ser juíza e lhe prender". Em casa, ainda tomei uma baita surra do meu pai. Naquela época, não se podia desrespeitar professor. (SANTOS, 2009, p.11). 
Trabalho entre a crença e o desânimo, porque sou o resultado "vitorioso" de um processo de escolarização no qual os pobres e negros/as "devem" fracassar, o que me deixa em tensão com os discursos de oprimida/opressora e na (des) confortável posição do empoderamento conseguido pela escolaridade, que, perante os alunos, é algo discutível, já que se eu estudei tanto por que ainda moramos no mesmo bairro? Se estudei tanto, por que ainda continuo ensinando nas escolas públicas da periferia?

São questionamentos também, de certo modo, formulados por meus colegas das escolas das redes municipal e estadual onde trabalho. Penso que uma negra que busca o doutorado é uma mulher negra começando outra luta pela mobilidade social, mas nem por isso precisa se separar da sua comunidade. Ao mesmo tempo, sinto a necessidade de um diálogo mais próximo com os alunos do ensino superior, no sentido de ampliar não só a minha formação, como também adentrar e conhecer outros territórios, conhecer outros modos de pensar.

Vejo nesse deslocamento uma consonância com o papel do intelectual orgânico proposto por Gramsci (apud HALL, 2006), como aquele que trabalha em duas frentes, ou seja, de um lado é o produtor de um trabalho teórico intelectual e, do outro, pode falar com conhecimento profundo acerca do seu lugar geopolítico, pois possui o conhecimento autêntico. A transmissão de suas ideias se dá através da função intelectual, e ele deve levá-las aos que não pertencem à classe intelectual. Para Hooks (1995, p.466), “[...] o trabalho intelectual é uma parte necessária da luta pela libertação, fundamental para os esforços de todas as pessoas oprimidas e/ou exploradas". O que não significa dizer que só existe essa saída

Buscar uma mobilidade social através da educação dentro de uma sociedade capitalista não pode ser confundido com empoderamento financeiro. Góis (2008), ao analisar a trajetória educacional de alunas de diferentes cursos da Universidade Federal Fluminense (Rio de Janeiro), observa que as escolhas das áreas do conhecimento acadêmico estão associadas a questões de classe: as mulheres mais pobres, ao escolherem seus cursos, pensam para além do desempenho no vestibular e anexam a essa questão as dificuldades de tempo de estudo e capital financeiro para se dedicar ao curso com os gastos que eles requerem. Assim, Medicina e Engenharia estão fora daquelas opções, mas não estão fora de seus sonhos. 
Posso afirmar que a negação de uma licença com ônus para o meu doutoramento representou não só mais um obstáculo, dentre tantos que as classes menos favorecidas precisam enfrentar, ao tentar conciliar trabalho e estudo, como também expôs o meu estado físico e mental a uma situação-limite, devido aos "malabarismos" que precisei empreender nessa luta. Horas de sono suprimidas, idas ao ortopedista, medicamentos para acalmar as dores musculares de um corpo escriba e leitor; tempo negado aos meus entes queridos e a mim mesma enquanto sujeito do desejo e das descobertas. Poderia ter sido diferente, se o tempo para minha formação acadêmica fosse respeitado, pelo significado histórico que esta conquista representa para o povo negro, pelo significado político que este fato reclama dentro da escola pública, na viabilidade do diálogo entre esse espaço e a Academia, diante das transformações socioculturais presentes em nossa sociedade.

Em relação à trajetória escolar feminina e às opções por um curso superior, Góis (2008) prossegue mostrando que há outro grupo de mulheres que oferece uma leitura dos elementos culturais presentes na história brasileira, no que diz respeito à internalização de que as mulheres negras não teriam o perfil para efetivamente lograr realizá-lo. Nessa ideologia, as mulheres negras são destinadas a atividades de menor valoração social. O passado escravagista e a forte presença feminina negra nas atividades domésticas reservam a esse grupo uma conotação de baixa ou nenhuma escolaridade.

Outro fato que não podemos desprezar, no que se refere às mulheres negras da minha geração, é, além da pobreza, a condição de analfabetos a que os pais estão submetidos. Para essas filhas primogênitas, a formação de uma identidade letrada é algo a se considerar no tempo/espaço como mais do que um esforço pessoal, tomando como análise o impacto do seu desenvolvimento escolar na constituição identitária como uma referência para seus (suas) irmãos (ãs) menores e a família de uma maneira geral.

Essa busca significa pleitear outros espaços de representação em um país que não reconhece o racismo como um traço cultural do seu povo. Vivemos sem conflitos raciais por "aceitar" como natural que, no mercado de trabalho, ocupemos as vagas dos serviços gerais ou que continuemos nas "casas de família" a limpar, lavar e cozinhar. Talvez, tenha sido esse o estranhamento da aluna, empregada doméstica, ao se deparar, na aula de Língua Portuguesa, com a professora negra, uma "igual", uma "negona rasta" 
que, em seu pré-julgamento, não "prestava" para ocupar aquele lugar (SANTOS, 2007, p.41):

Olha professora para lhe ser sincera, quando a senhora disse que MORAVA AQUI, eu pensei: NUM PRESTA, porque se prestasse estava ensinando num COLEGIO BOM DA CIDADE. A gente fica com o pé atrás, NE? Sei lá. (B1; s.f. , 41 a., empregada doméstica).

Esse imaginário acompanha as docentes negras até na universidade. Hooks (1995) fala da parca e incômoda presença das intelectuais negras dentro das universidades americanas, principalmente se essas intelectuais apresentarem algum engajamento que precisa de apoio. Nem todas as acadêmicas podem reclamar a posição de intelectual. A autora considera como intelectual alguém que lida com ideias, transgredindo fronteiras discursivas, pela necessidade de assim ter de agir.

É um lugar interdito dentro de uma sociedade patriarcal capitalista de supremacia branca, que atua para negar às mulheres a oportunidade de "seguir uma vida da mente" (HOOKS, 1995, p.468). A mulher negra não está fora do seu lugar se na escola ocupar o lugar de merendeira ou faxineira. É aquela que deve estar sempre disposta a servir com abnegação, porque todo mundo aprendeu, independente de ser branco ou negro, que as negras estão aí para atender às necessidades de outras pessoas, “[...] espera-se que limpem a sujeira de todos" (HOOKS, 1995, p.470).

\section{CONSIDERAÇÕES FINAIS}

Ao trazer para a tese a minha experiência cotidiana na mobilização política das identidades de mulher negra/professora/pesquisadora, estou ancorada no conceito feminista que supera a noção de dominação masculina, por considerar que o poder não é exclusividade dos homens. Decorre dessa afirmação, a minha simpatia pela teoria do ponto de vista feminista negro, que enfatiza a posição que ocupamos numa esfera de dominação interceptada pela multidimensionalidade inerente à raça, ao gênero e à classe social. Ao falar de dentro da minha cultura local, não quero dizer que eu seja mais ou menos oprimida que uma mulher branca pertencente à mesma classe social, conforme já me foi apontado por colegas que insistem em argumentar que passamos pelas mesmas 
dificuldades, apesar de terem a pele clara. Não discordo. No entanto, o lugar de onde vivencio as minhas experiências me é aquele que secularmente nos tem oferecido a paisagem desigual, racista e sexista da nossa sociedade.

Sendo assim, é compreensível o fracasso da minha tentativa em buscar a formação de um grupo de estudos dentro da unidade escolar, visto que os meus questionamentos pedagógicos ainda não resolvidos não encontraram igual inquietação ou sintonia com os demais envolvidos, talvez porque sejam complexos e tão subjetivos, ou talvez porque "[...] a aprendizagem criativa e pesquisadora requer que os participantes todos estejam igualmente perplexos perante os mesmos termos ou problemas" (ILLICH, 2007, p.24). Movo-me na esperança de que aquela proposta de formação docente "em serviço" tenha continuidade, também, em outras vozes de professores (as) pesquisadores (as) negros (as) para que as meninas e meninos, que os jovens e adultos, em cada sala de aula deste país, possam ser portadores de melhores notícias, não apenas no cenário educacional, como também nos diferentes cenários da sociedade.

\section{REFERÊNCIAS}

BAHIA. Secretaria da Educação. Estatuto do Magistério Público do Ensino Fundamental e Médio do Estado da Bahia. Salvador, 2002.

BENJAMIN, Walter. Magia e técnica, arte e política. Obras Escolhidas. São Paulo: Brasiliense, 1994.

BENTO, Maria Aparecida Silva. A mulher negra no mercado de trabalho. Estudos Feministas, Florianópolis, CFH/CCE/UFSC, v.3, n. 2, p.479-489, 1995.

BOLÍVAR, Antonio. Competências profissionais e crise de identidade. Pátio, Porto Alegre, Artmed, n.23, p.16-19, set./out. 2002.

CARIBÉ, Pedro. Enem revela "fosso" entre ensino público e privado. A Tarde, Salvador, 22 nov. 2008. Salvador \& Região Metropolitana, p. A7.

CARNEIRO, Sueli. Gênero, Raça e Ascensão Social. Estudos Feministas/Dossiê Mulheres Negras. Rio de Janeiro, IFCS/UFRJ - PPCIS/UERJ. v. 3, n. 2, p.544 -552, 1995. 
CHIES, Paula Viviane. Identidade de gênero e identidade profissional no campo do trabalho. Estudos Feministas, Florianópolis, CFH/CCE/UFSC, v.18, n.2, p.507-528, 2010 .

FREIRE, Paulo. Pedagogia da Autonomia: saberes necessários à prática educativa. 19.ed. São Paulo: Paz e Terra, 1996.

GIACOMINI, Sonia. Mulatas profissionais: raça, gênero e ocupação. Estudos Feministas, Florianópolis, CFH/CCE/UFSC, v.14, n. 1, p.85-101, jan./abr.2006

GÓIS, João Bosco Hora. Quando raça conta: um estudo de diferenças entre mulheres brancas e negras no acesso e permanência no ensino superior. Estudos Feministas, Florianópolis, CFH/CCE/UFSC, v.16, n. 3, p.743-768, set./dez. 2008.

HALL, Stuart. Questão multicultural. In: SOVIK, Liv (Org.) Da diáspora: identidades e mediações culturais. Trad. Adelaine La Guardia Resende et al. Belo Horizonte:

Humanitas: UFMG, 2006. p.50-94.

HENRIQUES, Ricardo. Raça e gênero no sistema de ensino: os limites das políticas universalistas na educação. Brasília: UNESCO, 2002.

HOOKS, Bell. Intelectuais negras. Estudos Feministas, Florianópolis, CFH/CCE/UFSC, v.3, n.2, p.464-479, 1995.

ILLICH, Ivan. Sociedade desescolarizada. Trad. Luciana Reis. Porto Alegre: Deriva, 2007.

MUNANGA, Kabengele. Rediscutindo a mestiçagem: identidade nacional versus identidade negra. Belo Horizonte: Autêntica, 2004.

PINHO, Osmundo de Araújo. O efeito do sexo: políticas de raça, gênero e miscigenação. Cad. Pagu, Campinas n. 23, dez. 2004. Disponível em: < http://www. scielo.br/scielo.php?pid=S0104-32004000200004\&script=sci_arttext. >.Acesso em: 20 jun. 2009.

SANTOS, Luislinda Valois. É sempre o negro o delinqüente: depoimento. Revista Muito/A Tarde, Salvador, 26 jul. 2009. Entrevista concedida a Tatiana Mendonça.

SANTOS, Terezinha Oliveira. Constituições identitárias numa turma da EJA: uma leitura para além das margens. 2007. Dissertação (Mestrado em Letras)- Universidade Federal da Bahia, Salvador, 2007.

RECEBIDO EM: 01 de novembro de 2012

APROVADO EM: 05 de dezembro de 2012 